\title{
Rheological study of gels based on chitosan and carbon nanotubes
}

\author{
M.A. Vigilato ${ }^{1}$, M.M. Horn ${ }^{2}$, V.C. Amaro Martins ${ }^{1}$ e A.M. de Guzzi Plepis ${ }^{1,2}$ \\ ${ }^{1}$ Instituto de Química de São Carlos - IQSC, Universidade de São Paulo \\ ${ }^{2}$ Programa de Pós-graduação Interunidades em Bioengenharia - EESC/FMRP/IQSC, Universidade de São Paulo, São Carlos, Brasil
}

Received: 25/11/2014; accepted: 28/12/2015

Available online: 30/06/2015

\begin{abstract}
Chitosan/carbon nanotubes associations have applications in tissue regeneration. This study reports on the rheological characterization of gels prepared by the mixture of chitosan and single-walled carbon nanotubes (SWCN). Rheological characterization was used to understand the internal structure of gels. Frequency tests of chitosan/SWCN showed that gels have elastic behavior, and an increment in SWCN concentration increases $\mathrm{G}^{\prime}$ modulus. Gels had an increase in viscosity values of more than 10 times as a function of SWCN concentration. The addition of carbon nanotubes modified the behavior of gels as observed by temperature results. For all gels prepared with SWCN, G' is higher than $\mathrm{G}^{\prime \prime}$ in the temperature range studied. SWCN changes the tridimensional network of chitosan and a new chain arrangement is obtained.
\end{abstract}

Keywords: Rheology, chitosan, carbon nanotubes.

\section{Introduction}

Chitin, the second most abundant biomaterial in nature, is a polysaccharide found in skeletons of crustaceans, insects and others species. The deacetylation of chitin results on a copolymer of $(1 \rightarrow 4)$-2-amino-2-deoxy- $\beta$-D-glucan and $(1 \rightarrow 4)$-2-acetamido-2-deoxy- $\beta$-D-glucan units block or randomly distributed throughout the biopolymer chain, named chitosan $[1,2]$.

Characteristics such as atoxicity, biodegradability, biocompatibility and ability to take different forms contribute to the wide use of chitosan in medical and pharmaceutical fields [3]. However, chitosan mechanical properties are not appropriate for its variety of applications $[4,5]$.

Another important material for applications in biotechnology is the carbon nanotube. This material is formed by the winding of carbon sheets called graphene and presents cylindrical shape with diameter measuring on the nanometer scale and lengths around several microns. Moreover, $\mathrm{CN}$ can be found as a single-walled structure (SWCN) or a multi-walled structure (MWCN) [6]. Due to its remarkable thermal, mechanical and electrical properties, carbon nanotubes has been largely used in composites with polymers as reinforcement of these properties $[7,8]$.

Rheometry is a technique used to characterize new materials to understand its internal structure. Studies about rheological characterization of chitosan/carbon nanotubes were not found in literature. Thus, the aim of this-paper was to prepare gels composed by the mixture between chitosan and single-walled carbon nanotubes and to study their rheological properties.

\section{Experimental}

\subsection{Materials}

Chitosan (molecular average weight of $4.37 \times 10^{5} \mathrm{~g} \mathrm{~mol}^{-1}$ and degree of acetylation of $9 \%$ ) was obtained from squid pens and characterized as previously described [9]. Single-walled carbon nanotubes (SWCN) was supplied by Sigma-Aldrich and SWCN surface was functionalized using a 1:2 $(\mathrm{v} / \mathrm{v})$ mixture of sulfuric acid $(98 \%)$ and nitric acid $(65 \%)$ as described by Wang et al. [10]. Surface functionalization allows the formation of carboxylic groups in SWCN surface [8].

\subsection{Sample preparation}

A $1 \%(w / w)$ chitosan solution was prepared by dissolution in $1 \%$ acetic acid. After that, $0.10,0.25$ and $0.50 \mathrm{mg}$ of SWCN were added to chitosan solution and then stirred using a mechanic agitator followed by homogenization in an ultrasonic bath (Unique USC $1400 \mathrm{~A}$ ) for $60 \mathrm{~min}$. Samples were labeled CCN10, CCN25 and CCN50 respectively. A chitosan sample (CHI) was prepared to allow the comparison with samples containing carbon nanotubes.

\subsection{Rheological characterization}

The rheological properties were investigated using a stress-controlled Rheometer (AR-1000N - TA Instruments), fitted with a stainless steel cone/plate geometry ( 2 ' cone angle, $20 \mathrm{~mm}$ cone diameter) with the gap set at $69 \mu \mathrm{m}$ and a Peltier plate for temperature control.

\footnotetext{
* Corresponding author: Tel.: +55 (16) 3373-9976

E-mail address: amplepis@iqsc.usp.br (A. M. de Guzzi Plepis)
} 


\subsubsection{Dynamic rheological measurements}

At first, the linear viscoelastic region was determined with a stress sweep in the range 0.01 to $100 \mathrm{~Pa}$ at a constant frequency of $1.0 \mathrm{~Hz}$. All the subsequent measurements were conducted within the linear viscoelastic regime, where the dynamic storage modulus ( $\left.\mathrm{G}^{\prime}\right)$ and loss modulus $(G$ ') are independent of the strain amplitude. The strain value selected for this study was $10 \%$.

Frequency sweeps were performed from 0.05 to $300 \mathrm{rad} \mathrm{s}^{-1}$ at $25{ }^{\circ} \mathrm{C}$ and a constant strain of $10 \%$. Dynamic temperature sweep tests were made after equilibration at the initial temperature of $20{ }^{\circ} \mathrm{C}$ and heated from 20 to $75^{\circ} \mathrm{C}$ at a rate of $5{ }^{\circ} \mathrm{C} \mathrm{min}{ }^{-1}$ and a constants frequency of $1.0 \mathrm{~Hz}$ and $10 \%$ of strain.

\subsubsection{Steady flow measurements}

The experiments were carried out with a shear rate ranging from 0.1 to $1000 \mathrm{~s}^{-1}$ at $25^{\circ} \mathrm{C}$. The flow behavior of gels was determined applying the Ostwald de Waele model where the mathematical interpretation of the relationship between the shear stress and the shear rate is described by Equation 1:

$$
\sigma=K \dot{\gamma}^{n}
$$

where $K$ is the consistency coefficient ( $\mathrm{Pa} \mathrm{s}$ ) and $\sigma$ is the shear stress $(\mathrm{Pa}), \dot{\gamma}$ is the shear rate (s-1) and $n$ the flow behavior index (dimensionless).

\section{Results and Discussion}

All gels were homogeneous, without any precipitated material and it was possible to observe that the concentration of carbon nanotubes influenced the color of gels, since with an increase in concentration, gels became grayer. Electrostatic interactions occur between chitosan and carbon nanotubes protoned amino groups of chitosan and carboxylic groups of functionalized carbon nanotube wall (Figure 1).
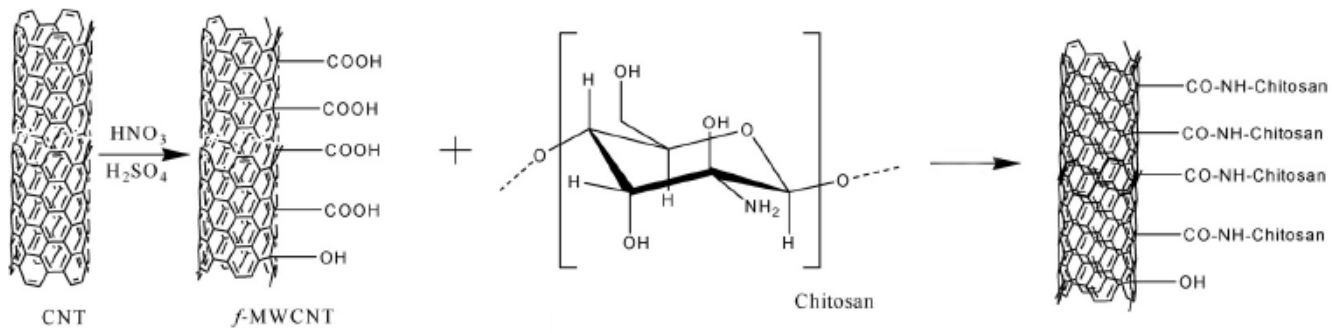

Figure 1. Chitosan/carbon nanotubes interaction [8].

\section{Dynamic rheological measurements}

Frequency sweep tests were carried out in the linear viscoelastic region. Figure 2 shows the dependence of $G^{\prime}$ and $\mathrm{G}^{\prime \prime}$ with frequency at $25^{\circ} \mathrm{C}$. An increase in $\mathrm{G}^{\prime}$ and $\mathrm{G}^{\prime \prime}$ values was observed for all gels within the frequency range studied. This behavior is related to the relaxation time of chains. At low frequency, relaxation time is larger and the chains can relax slowly, reducing $\mathrm{G}^{\prime}$ and $\mathrm{G}^{\prime \prime}$. However, when polymer chains were deformed at higher frequency, the entangled chains have less time for re-orientation, which increases the moduli [11].

For CHI gel, in the frequency range studied, $\mathrm{G}^{\prime \prime}$ was higher than $\mathrm{G}^{\prime}$ and the gel has a viscous characteristic. After nanotubes addition $\mathrm{G}^{\prime}$ is dominant over $\mathrm{G}^{\prime \prime}$ and the gels have an elastic behavior. The storage modulus ( $\left.G^{\prime}\right)$ can be considered as a measure of the extension of the gel network formation and higher values for $G$ ' means a stronger gel [12]. At a frequency equal to $1.0 \mathrm{rad} \mathrm{s}^{-1}, \mathrm{G}^{\prime}$ modulus values were found as: $200 \mathrm{~Pa}$ (CCN10), $30 \mathrm{~Pa}$ (CCN25) and $15 \mathrm{~Pa}(\mathrm{CCN} 50)$. This behavior showed that carbon nanotubes concentration decreased the $\mathrm{G}^{\prime}$ values due to an increase in chitosan/carbon nanotubes associations and can reflected an increase of mechanical properties of the material.

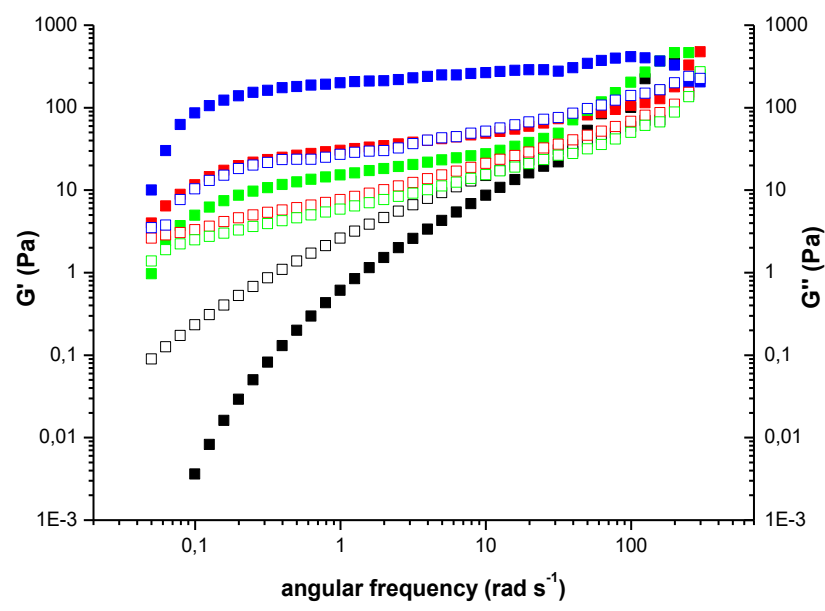

Figure 2. $\mathrm{G}^{\prime}$ e $\mathrm{G}^{\prime \prime}$ as a function of frequency for: CHI - - - G', - $\square-\mathrm{G}^{\prime}$; CCN10 - - - G', - $\square-$ G', CCN25 - - G', - $\square-\mathrm{G}^{\prime}$ ' and CCN50 - - - G', $-\square-\mathrm{G}$,

Figure 3 shows the storage and loss moduli as a function of temperature for all gels. Gelation temperature is usually defined as the sol/gel transition temperature at which $\mathrm{G}^{\prime}=\mathrm{G}^{\prime \prime}$.

For CHI gel, the moduli curves as function of temperature can be divided in two parts. In the first region, 
where $\mathrm{G}^{\prime}$ is lower than $\mathrm{G}^{\prime \prime}$, the gel shows the behavior of a liquid. Subsequently, the sharp increase in $\mathrm{G}^{\prime}$ is related to the partial formation of chitosan cluster through hydrophobic interactions between chitosan chains [13]. In the second region, both $\mathrm{G}^{\prime}$ and $\mathrm{G}^{\prime \prime}$ increase with an increase of temperature and $\mathrm{G}^{\prime}$ is higher than $\mathrm{G}^{\prime \prime}$, indicating that an elastic gel network has formed [14]. For CHI gel, the gelation temperature is $59{ }^{\circ} \mathrm{C}$ in accordance with previous study [15].

The addition of carbon nanotubes modified the behavior of gels. For all gels prepared with SWCN, G' is higher than $\mathrm{G}^{\prime \prime}$ in the temperature range studied. SWCN changes the tridimensional network of chitosan and a new chain arrangement is obtained. For CCN50 gel, at higher concentration of SWCN, $G^{\prime}$ and $G^{\prime \prime}$ moduli had a similar behavior to the observed for $\mathrm{CHI}$ gel with a small increase in moduli at low temperature values and an abrupt increase around $50{ }^{\circ} \mathrm{C}$. SWCN addition alters the behavior of gels and $\mathrm{G}^{\prime}$ became higher than $\mathrm{G}^{\prime \prime}$. This result confirms that different networks were obtained after SWCN addition, and they were dependent of SWCN concentration.

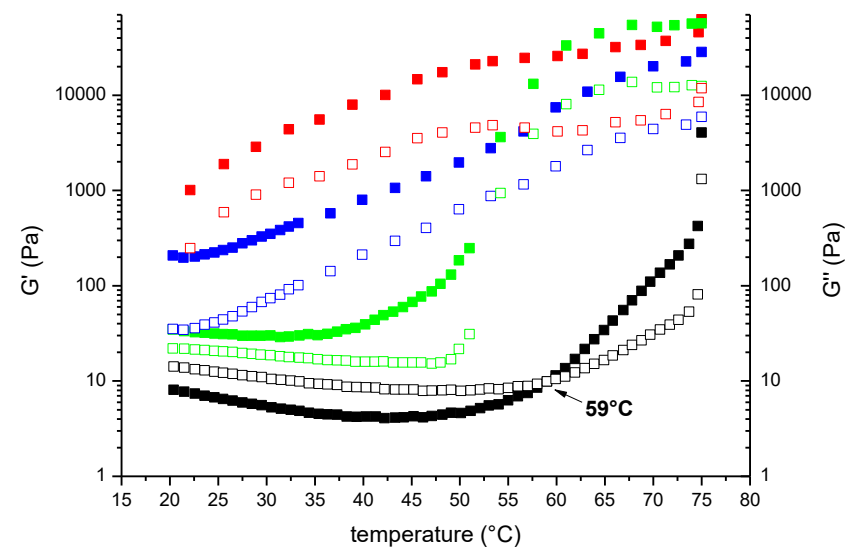

Figure 3. $\mathrm{G}^{\prime}$ e $\mathrm{G}^{\prime \prime}$ as a function of temperature for:

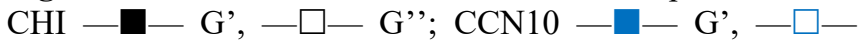
G', CCN25 - - - G', - $\square-\mathrm{G}$ ', and CCN50-口- G', $-\square-\mathrm{G}^{\prime}$.

\section{Flow measurements}

Figure 4 shows the behavior of viscosity as a function of shear rate for all samples. Chitosan/carbon nanotubes blends showed a shear thinning or pseudoplastic behavior in the studied range, i.e. the viscosity decreased with the applied shear force.

As seen from this figure, viscosity values of samples decreased with an increase in shear rate, indicating that the gels showed shear thinning behavior. The shear thinning behavior can be explained by two reasons: first one, by hydrodynamic forces generated during the shear break of structural units in solution and second one by disruption of polysaccharide entanglements and the orientation of the biopolymer chains.

Carbon nanotubes influence the flow behavior of gels, as SWCN addition increases the viscosity values. For example, at shear rate of $1.0 \mathrm{~s}^{-1}$, after SWCN addition, an increase in viscosity values more than 15 times was observed when compared to $\mathrm{CHI}$ gel $\left(2.2 \mathrm{~Pa} \mathrm{~s}^{-1}\right)$. At its shear rate, viscosity values were $32 \mathrm{~Pa} \mathrm{~s}^{-1}$ (CCN10), $30 \mathrm{~Pa} \mathrm{~s}^{-1}$ (CCN25) and $22 \mathrm{~Pa} \mathrm{~s}^{-1}$ (CCN50) showing that SWCN concentration increased the viscosity of gels. SWCN interacts with chitosan and an increase in SWCN concentration generated gels with more difficulty to flow.

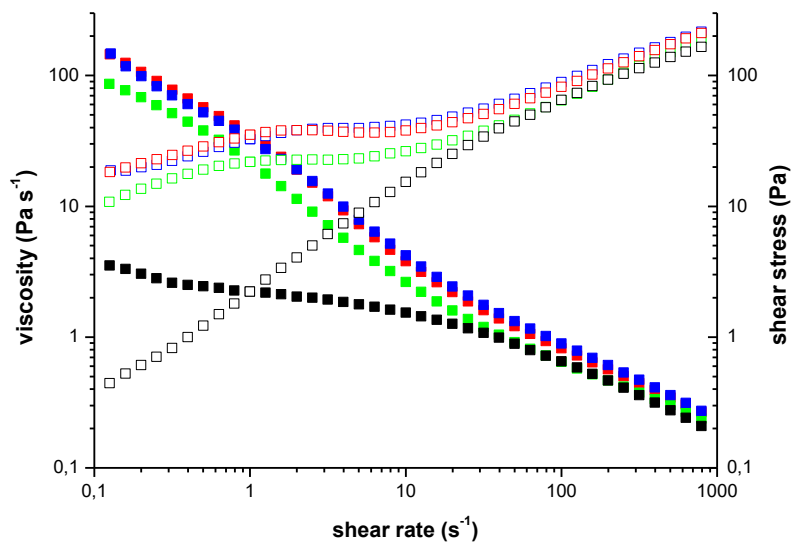

Figure 4. Viscosity as function of shear rate for: $\mathrm{CHI}-\square-$; $\mathrm{CCN} 10-\square-$; $\mathrm{CCN} 25-\square-$; CCN50 — _ and shear stress as function of shear rate for: CHI - $\square$-; $\quad$ CCN10 - $\square$-; $\quad$ CCN25 - $\square$; CCN50- $\square-$.

The flow behavior of non-Newtonian fluids can be verified by many models and among them the mostly used is the Ostwald de Waele model. This model was used to fit the data obtained from rheological measurements of chitosan and chitosan/carbon nanotube gels. $K, n$ and $\mathrm{R}^{2}$ calculated values at $25{ }^{\circ} \mathrm{C}$ are listed in Table 1 . As seen, $\mathrm{R}^{2}$ values were found to be very close to unit confirming that the model was adequate to fit the rheological data.

Table 1. Fitted parameters for Ostwald de Waele model

\begin{tabular}{cccc}
\hline Gels & $K(\mathrm{~Pa} \mathrm{~s})$ & $n$ & $\mathrm{R}^{2}$ \\
\hline CHI & 6.50 & 0.4890 & 0.9948 \\
\hline CCN10 & 17.34 & 0.3743 & 0.9957 \\
\hline CCN25 & 14.93 & 0.3921 & 0.9961 \\
\hline CCN50 & 11.41 & 0.4700 & 0.9953 \\
\hline
\end{tabular}

The values for $K$ and $n$ were in the range of $17-6.50 \mathrm{~Pa} \mathrm{~s}$ and $0.48-0.37$, respectively. Since $K$ value has a direct relationship with viscosity, results showed that SWCN nanotubes addition increases the $K$ values and consequently the viscosity of gels. In the absence of carbon nanotubes, chitosan gel has the lower viscosity values as chitosan networks interacts only with other chitosan networks by intramolecular interactions, as hydrogen bounds [16]. After SWCN addition, occurs an interaction between the two components and the gels have a difficult to flow, increasing $K$ values. As claimed before, gels had a shear thinning behavior, since $n$ values were lower than unity [16]. 


\section{Conclusion}

Single-walled carbon nanotubes addition modified the rheological properties of chitosan gels. After nanotubes addition, gels had $\mathrm{G}^{\prime}$ dominant over $\mathrm{G}^{\prime \prime}$ that represents an elastic behavior. In addition, SWCN concentration increased $\mathrm{G}^{\prime}$ modulus that represents an increase in chains entanglement. SWCN changed the tridimensional network of chitosan and a new chain arrangement was obtained that modified the viscosity characteristics of gels. An increase in viscosity values reflects in gels with more difficulty to flow.

\section{Acknowledgements}

M. M. H. thanks the financial support of PNPD/Capes program.

\section{References}

[1] Pighinelli L, Kucharska M. Chitosan-hydroxyapatite composites. Carbohydr Polym 2013; 93:256-262. [Google Scholar] [CrossRef]

[2] Thein-Han WW, Misra RDK. Biomimetic chitosannanohydroxyapatite composite scaffolds for bone tissue engineering. Acta Biomater 2009; 5:1182-1197. [Google Scholar] [CrossRef]

[3] Jayakumar R, Menon D, Manzoor K, Nair SV, Tamura H. Biomedical applications of chitin and chitosan based nanomaterials - A short review. Carbohydr Polym 2010; 82:227-232. [Google Scholar] [CrossRef]

[4] Aryaei A, Jayatissa AH, Jayasuriya AC. Mechanical and biological properties of chitosan/carbon nanotube nanocomposite films. J Biomed Mater Res 2014; 102A:2704-2712. [Google Scholar] [CrossRef]

[5] Elsabee MZ, Abdou ES. Chitosan based edible films and coatings: A review. Mater Sci Eng C 2013; 33:1819-1841. [Google Scholar] [CrossRef]

[6] Beg S, Rizwan M, Sheikh AM, Hasnain MS, Anwer K, Kohli K. Advancement in carbon nanotubes: basics, biomedical applications and toxicity. J Pharm Pharmacol 2011; 63:141-163. [Google Scholar] [CrossRef]

[7] Nardecchia S, Serrano MC, Gutiérrez MC, Ferrer ML, Monte F. Modulating the cytocompatibility of tridimensional carbon nanotubo based scadffolds. J Mater Chem B 2013; 1:3064-3072. [Google Scholar] [CrossRef]

[8] Venkatesan J, Ryu B, Sudha PN, Kim SK. Preparation and characterization of chitosan-carbon nanotube scaffolds for bone tissue engineering. Int J Biol Macromol 2012; 50:393-402. [Google Scholar] [CrossRef]

[9] Horn MM, Martins VCA, Plepis AMG. Interaction of anionic collagen with chitosan: Effect on thermal and morphological characteristics. Carbohydr Polym 2009; 77:239-243. [Google Scholar] [CrossRef]
[10] Wang SF, Shen L, Zhang WD, Tong YJ. Preparation and mechanical properties of chitosan/carbon nanotubes composites. Biomacromolecules 2005; 6:3067-3072. [Google Scholar] [CrossRef]

[11] Wyss HM, Miyashaki K, Mattson J, Hu Z, Reichman D, Weitz D. Strain-Rate Frequency Superposition: A Rheological Probe of Structural Relaxation in Soft Materials. Phys Rev Lett 2007; 98(23):238303/1-238303/4. [Google Scholar] [CrossRef]

[12] Deng G, Tang C, Li F, Jiang H, Chen Y. Covalent Cross-Linked Polymer Gels with Reversible Sol-Gel Transition and Self-Healing Properties. Macromolecules 2010; 43:1191-1194. [Google Scholar] [CrossRef]

[13] Corrias F, Dolz M, Herraez M, Diez-Sales O. Rheological properties of progesterone microemulsions: influence of xanthan and chitosan biopolymer concentrations. J Appl Polym Sci 2008; 110(2):1225-1235. [Google Scholar] [CrossRef]

[14] Aliaghaie M, Mirzadeh H, Dashtimoghadam E, Taranejoo S. Investigation of gelation mechanism of an injectable hydrogel based on chitosan by rheological measurements for a drug delivery application. Soft Matter 2012; 8:7128-7137. [Google Scholar] [CrossRef]

[15] Horn MM, Martins VCA, Plepis AMG. Effects of starch gelatinization and oxidation on the rheological behavior of chitosan/starch blends. Polym Int 2011; 60:920-923. [Google Scholar] [CrossRef]

[16] Tang YF, Ym, Du, Hu XW, Shi XW, Kennedy JF. Rheological characterization of novel thermosensitive chitosan/poly(vinyl alcohol) blend hydrogel. Carbohydr Polym 2007; 67:491-499. [Google Scholar] [CrossRef] 